\title{
Retrospective Evaluation of Intussusception in Under-Five Children in Nigeria
}

\author{
Beckie Nnenna Tagbo ${ }^{*}$, Jason Mwenda ${ }^{2}$, Christopher Eke ${ }^{3}$, Tagbo Oguonu ${ }^{3}$, \\ Sebastin Ekemze ${ }^{4}$, Uchechukwu Obiora Ezomike ${ }^{4}$, Benedict Edelu ${ }^{3}$, Ogechukwu Amadi ${ }^{5}$, \\ Ifeyinwa Okeke ${ }^{5}$, Okechukwu Ani ${ }^{5}$, Roservelt Okechukwu Nnani6, Vina Okafor ${ }^{6}$, \\ Henrietta Uche Okafor'1, Egbuna Obidike3 ${ }^{3}$ Emmanuel Abanida ${ }^{7}$, Chris Elemuwa7, \\ Toyin Odetunde ${ }^{8}$ \\ ${ }^{1}$ Institute of Child Health and Department of Paediatrics, University of Nigeria Teaching Hospital, Enugu, Nigeria \\ ${ }^{2}$ World Health Organization Regional Office for Africa (WHO/AFRO), Brazzaville, Republic of Congo \\ ${ }^{3}$ Department of Paediatrics, University of Nigeria Teaching Hospital, Enugu, Nigeria \\ ${ }^{4}$ Department of Paediatric Surgery, University of Nigeria Teaching Hospital, Enugu, Nigeria \\ ${ }^{5}$ Department of Paediatrics, Enugu State University Teaching Hospital, Enugu, Nigeria \\ ${ }^{6}$ Institte of Child Health, University of Nigeria Teaching Hospital, Enugu, Nigeria \\ ${ }^{7}$ National Primary Health Care Development Agency, Federal Ministry of Health, Abuja, Nigeria \\ ${ }^{8}$ Department of Paediatric Surgery, Enugu State University Teaching Hospital, Enugu, Nigeria \\ Email: ${ }^{\text {tagbobeckie@gmail.com }}$
}

Received 3 June 2014; revised 5 July 2014; accepted 24 July

Copyright (C) 2014 by authors and Scientific Research Publishing Inc.

This work is licensed under the Creative Commons Attribution International License (CC BY).

http://creativecommons.org/licenses/by/4.0/

c) (i) Open Access

\section{Abstract}

Background: Assessment of the safety profile of the new rotavirus vaccines in Africa requires base-line epidemiological data on intussusception. Hence, this study was aimed at describing the prevalence and associated factors of intussusception in under-five children in Enugu, Southeast, Nigeria. Methods: This was a retrospective descriptive study involving the sixty reported cases of intussusception in under-five children admitted in a hospital in Enugu between 2007 and 2012. Cases of intussusception were selected using the Brighton collaboration intussusception working group level I diagnostic criteria. Information sought from the patients' folders included demographic characteristics and clinical manifestations including history of previous rotavirus vaccination, duration of illness prior to presentation, diarrhoea, vomiting, passage of red currant jelly- like stool, abdominal mass and distension, method of diagnosis, treatment option(s) employed and their outcomes. The data was analyzed using SPSS version 17.0. Results: The majority of the cases were aged less than one year $(53 ; 88.3 \%)$ while the average incidence of intussusception was 0.1 per 1000 . None of the cases had received rotavirus vaccinations. The common clinical presentations were vomiting, $55(17.2 \%)$, passage of red currant stool 50 (15.6\%), fever 50

"Corresponding author. 
(15.6\%) and abnormal/absent bowel sound 43 (15.9\%). Diagnosis was essentially with the aid of abdominal ultrasonography, 38 (63.3\%) while surgery (laparotomy) was the treatment of choice in most cases $48(80.0 \%)$. The case fatality rate was $3(5.0 \%)$. Conclusion: None of the cases studied could be directly linked to rotavirus vaccinations. But seasonal peak incidence coincided with rotavirus diarrhea peak incidence. Efforts should be made to institute post-rotavirus vaccine licensure prospective surveillance study in order to fully determine any relationship between rotavirus vaccination and intussusception in Enugu, South east, Nigeria.

\title{
Keywords
}

\author{
Intussusception, Children, Rotavirus, Surgery, Bloody Stool, Nigeria
}

\section{Introduction}

Intussusception is the most common cause of intestinal obstruction in infants and young children between the ages of 3 months and 6 years [1]. It is an acute surgical emergency and if it is not diagnosed and treated promptly, the blood supply to the bowel may be obstructed causing bowel infarction and perforation. Untreated cases of intussusceptions therefore are potentially lethal.

Accurate estimates of the incidence of acute intussusception are unavailable for most developing and developed countries. In developed countries the incidence of acute intussusception in infants and children is reported to be between 0.5 and 4.3 cases per 1000 live births or 0.66 to 1.2 cases per 1000 children under one year of age [2].

In Africa the number of cases of intussusception varies widely between hospitals from 60 cases per year in Cairo to 1 to 2 cases per year in centres in Ethiopia and Nigeria respectively [2]. However, these individual centres may under-estimate the incidence since they report only those cases that present to hospital settings.

In some regions, the diagnosis of intussusception may not be confirmed in some children because of limited radiologic facilities available [2] and in a few cases there may be spontaneous reduction before radiologic diagnosis is established [3].

In order to overcome these drawbacks, Bines et al. [4] formulated a clinical case definition for the diagnosis of intussusception. With a sensitiveness of $97 \%$ and specificity that ranged between $87 \%$ and $91 \%$, this may be a very helpful tool especially in places with limited facilities.

The causes of intussusceptions remain largely unknown, however pointers have been alluded to appendiceal stump, Merckel's diverticulum, intestinal polyp, coeliac disease, cystic fibrosis, lymphosarcoma and HenochSchonlein purpura [5].

More importantly, association between intussusception and human rotavirus gastroenteritis as well as infections due to adenoviruses [1] [2] [6] [7] and rotavirus vaccination has not been well understood.

The first approved vaccine against rotavirus diarrhoea, a tetravalent, rhesus-based vaccine (Rotashield $\AA$, Wyeth Lederle vaccine, Philadelphia) approved by the United States Food and Drug Administration for human use was withdrawn from the market in 1998 [8]-[10] as a result of reports of association between intussusception among children with recent rotavirus vaccination.

Rotavirus is the most common cause of severe dehydrating diarrhoea among infants and young children [11] resulting in about 453,000 mortalities in children $<5$ years of age annually worldwide (with 232,000 deaths occurring in sub-Saharan Africa) [12] [13].

As a result of substantial morbidity and mortality worldwide caused by rotavirus, the World Health Organization and Global Alliance for vaccine and Immunization (GAVI) identified rotavirus vaccines as a priority for development [14] and subsequent introduction [15].

Over the past two decades there have been major efforts to develop safe and effective rotavirus vaccines that can prevent significant morbidity and mortality associated with rotavirus infection particularly in developing countries [10].

As a result of global partnerships and efforts, newer vaccines have been developed and tested extensively during clinical trials in different regions of the world. These vaccines Rotarix ${ }^{\circledR}$ and Rotateq ${ }^{\circledR}$ have been found to be safe and effective and are now being introduced in immunization programs of both developed and devel- 
oping countries [16] [17].

However, there remains a low risk of intussusception, when the vaccines are administered outside the strict immunization schedule and in regions where the baseline risk of intussusception is high or is unknown [18]-[20].

These new vaccines have been introduced in the national immunization programmes in many countries including some in sub-Saharan Africa.

Data on pre-vaccine intussusception rates in developing countries especially in the sub-Saharan Africa are required to facilitate informed decision making about use of new rotavirus vaccines [21].

Nigeria plans to roll out the new rotavirus vaccine in her routine vaccinations program, and therefore there is urgent need to ascertain the baseline data as it relates to intussusception.

Hence, the aim of the current study was to determine the epidemiology of intussusception in children less than 5 years of age.

\section{Materials and Methods}

This retrospective descriptive study was conducted in two tertiary health facilities in Enugu (University of Nigeria Teaching Hospital (UNTH), Enugu and Enugu State University of Science and Teaching (ESUT) Teaching Hospital, Park Lane, Enugu).

Ethical clearance for the study was sought from the Health Ethics and Research Committee of University of Nigeria Teaching Hospital, Ituku-Ozalla, Enugu.

The admission registers of the children's emergency unit and paediatric surgical ward of each of the teaching hospitals were used to identify all cases with diagnosis of intussusception in children aged less than 5 years of age over a five year period (8th January, 2007-7th January, 2012).

Further the cases of intussusception were selected on the basis of Brighton collaboration intussusception working group protocol level I criteria [22].

A total of 60 cases that met the criteria were selected.

Relevant information obtained from the records of the 60 eligible cases included demographic data like age, gender and clinical manifestations including duration of illness prior to presentation at the hospital, symptoms at presentation like diarrhoea, vomiting, abdominal distension, passage of red currant jelly like stool, investigations employed, treatment, findings at surgery, evidence of mode of diagnosis corresponding with surgical confirmation of intussusception, duration of hospitalization and treatment outcome.

The data of each selected case was entered into a semi-structured questionnaire.

The data was subsequently analyzed using SPSS version 17.0 and presented in tables and charts.

\section{Results}

A total of 60 cases were studied comprising 38 males and 22 females giving a female to male ratio of 1:1.7.

The subjects were aged 3 months to 59 months with a mean age of 7.69 months and median age of 6 months.

Majority of the cases studied were infants, less than 12 months of age, $53(88.3 \%)$. This is as shown in Table 1 and Figure 1.

Table 1. Age and gender distribution of cases of intussusception.

\begin{tabular}{cc}
\hline Age (months) & $\mathrm{N}(\%)$ \\
\hline $3-11$ & $53(88.3)$ \\
$12-<24$ & $6(10.0)$ \\
$24-<35$ & $0(0.0)$ \\
$36-<48$ & $0(0.0)$ \\
$48-<60$ & $1(1.7)$ \\
Total & $60(100.0)$ \\
Gender & \\
Male & $38(63.3)$ \\
Female & $22(36.7)$ \\
Total & $60(100.0)$ \\
\hline
\end{tabular}




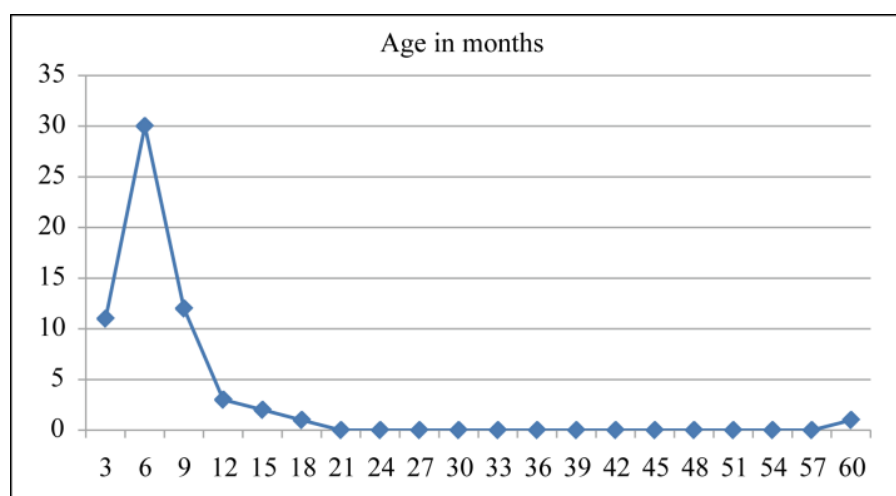

Figure 1. Cumulative age incidence.

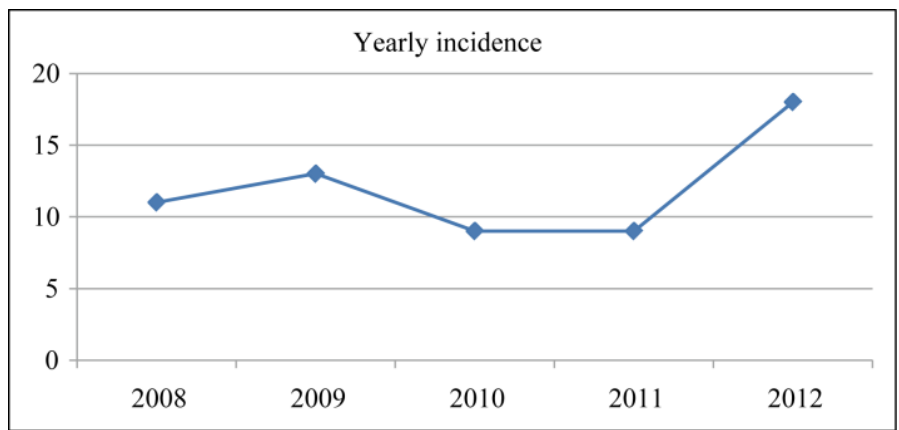

Figure 2. Yearly incidence of Intussusceptions case.

Over the five year period of the study (2008 to 2012) the yearly incidence was highest in 2012 where 18 cases were reported giving an annual incidence of 0.17 per 1000 while the average incidence was 0.1 per 1000 . The yearly incidence of the intussusception cases is as shown in Figure 2.

Although, Nigeria has not introduced rotavirus vaccine in routine immunization program, rotavirus vaccine is available in the private hospitals. Among all the cases of intussusception studied, none received rotavirus vaccination. However in about 40 (66.7\%) cases the caregivers did not know whether their wards received rotavirus vaccination while $18(30.0 \%)$ reported that their children did not receive the vaccine at all.

In terms of seasonality the majority of the cases occurred in the dry season (between December and April). Figure 3(a) and Figure 3(b) show the seasonal variation of rotavirus presentation over the five year period of review.

The aetiology of intussusception was reported to be idiopathic in $23(38.3 \%)$ cases while the rest were unknown.

In Table 2, the commonest clinical presentations were vomiting $55(17.2 \%)$, passage of bloody stool, 50 $(15.6 \%)$, fever, $50(15.6 \%)$, blood stained finger on rectal examination, $51(18.8 \%)$, abnormal/absent bowel sound, 43 (15.9).

The mean duration of symptoms before presentation was 4.1 days (10 hours to 8 days).

Various investigatory tools including plain abdominal X-rays, contrast radiography, abdominopelvic ultrasound were employed to make the diagnosis of the cases of intussusception in $9(15.0 \%), 1(1.7 \%)$ and 38 $(63.3 \%)$ of the cases respectively while in 14 cases $(23.3 \%)$, no method of diagnosis was reported. Figure 4 shows the various methods of investigations applied.

However, it was observed that in some cases more than one investigation was employed in the diagnosis.

Also, the investigative tools accurately confirmed the diagnosis of intussusception in $39(65.0 \%)$ cases.

In terms of the different treatment modalities used, 48 (80.0\%) had laparotomy, out of which $19(31.7 \%)$ had bowel resection while $28(46.7 \%)$ were reduced at surgery (Table 3$)$.

However, some had more than one type of treatment. This is shown in Table 3.

In terms of emergency treatment of cases $14(23.3 \%)$, and 20 (33.3\%) had surgery within 10 and 30 hours of 


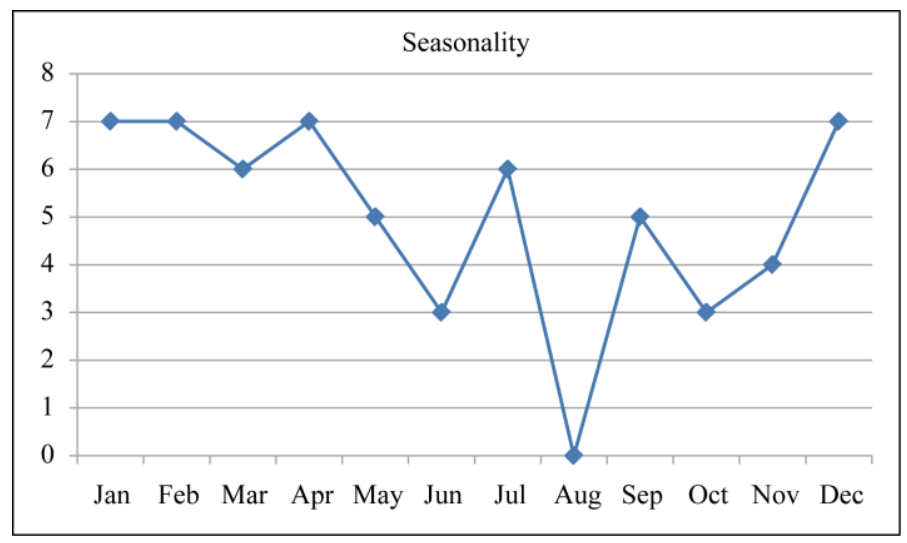

(a)

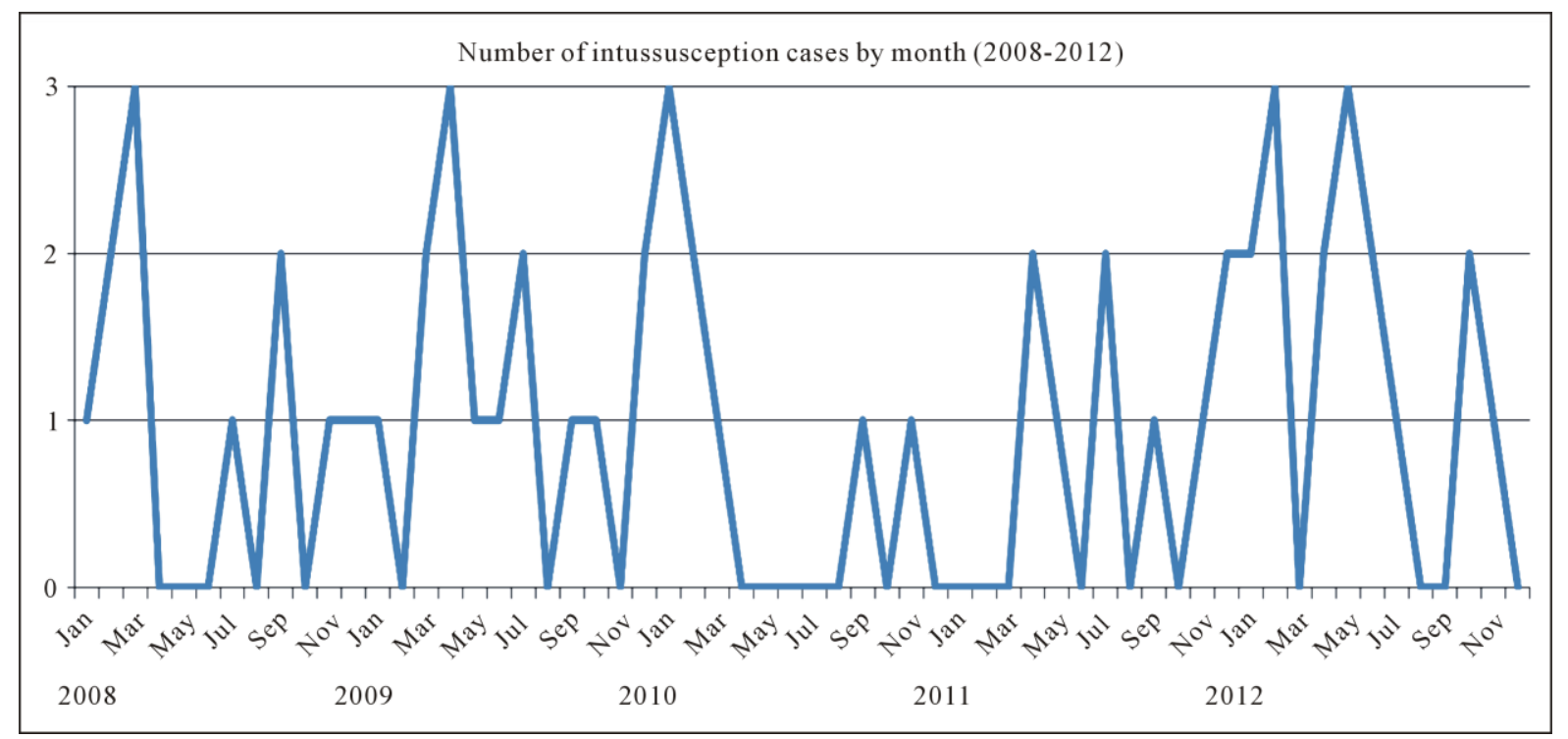

(b)

Figure 3. (a) Seasonality of cases of intussusception (monthly cumulative); (b) Yearly seasonality of intussusception.
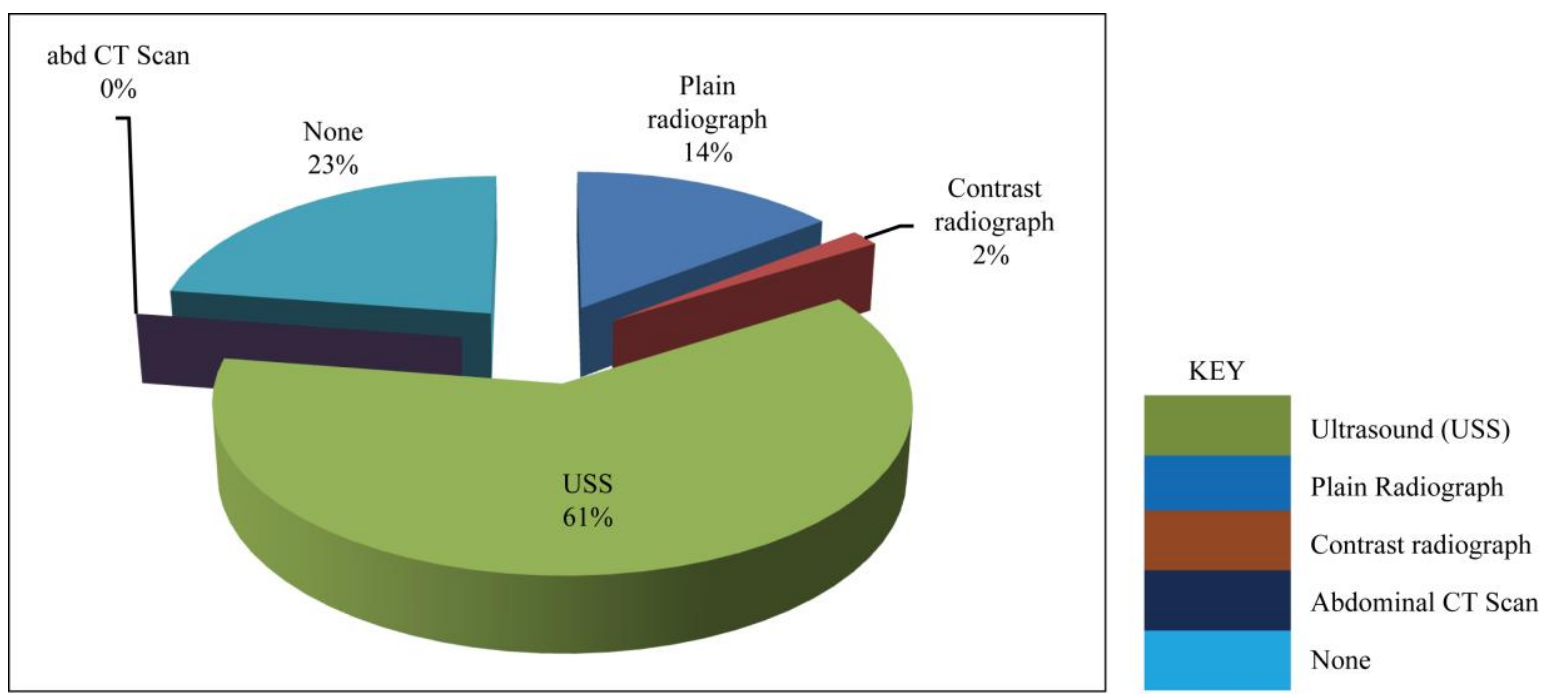

Figure 4. Methods of investigation for cases of intussusception. 
Table 2. Clinical symptoms and signs of intussusception cases.

(a)

\begin{tabular}{ccc}
\hline Clinical symptoms & $\mathrm{N}$ & $(\%)$ \\
\hline Vomiting & 55 & 17.2 \\
Bloody stool (Red currant stool) & 50 & 15.6 \\
Fever & 50 & 15.6 \\
Abdominal pain & 34 & 10.6 \\
Passage of blood per rectum & 32 & 10.0 \\
Diarrhoea & 30 & 9.4 \\
Abdominal distension & 28 & 8.8 \\
Constipation & 11 & 3.4 \\
Screaming attacks & 11 & 3.4 \\
Total & 320 & 100.0 \\
\hline
\end{tabular}

(b)

\begin{tabular}{ccc}
\hline Clinical Signs & $\mathrm{N}$ & $(\%)$ \\
\hline Blood stained finger on PR & 51 & 18.8 \\
Abnormal/absent bowel sound & 43 & 15.9 \\
Abdominal distension & 33 & 12.2 \\
Irritability & 32 & 11.8 \\
Abdominal mass & 30 & 11.1 \\
Dehydration & 25 & 9.2 \\
Rectal mass & 21 & 7.7 \\
Abdominal tenderness & 16 & 5.9 \\
Lethargy & 11 & 4.1 \\
Rectal prolapse & 8 & 3.0 \\
Shock & 1 & 0.4 \\
Total & 271 & 100.0 \\
\hline
\end{tabular}

Table 3. Treatment modality.

\begin{tabular}{cc}
\hline Type of treatment & $\mathrm{No}^{*}$ \\
\hline Laparotomy & 48 \\
Bowel resection & 19 \\
Hydrostatic education & 4 \\
Reduced at surgery & 28 \\
Others & 0 \\
\hline
\end{tabular}

*Some had more than one type.

admission respectively.

In Table 3, 56 (93.3\%) cases were successfully treated and discharged home while $3(5.0 \%)$ demised following complications of cases prior to presentation mainly due to severe sepsis and septic shock, one case (1.7\%) was discharged against medical advice. 


\section{Discussion}

The average incidence of intussusception, (0.1/1000) reported in the current study was similar to the findings by Ekenze et al. [23] in the same study locale, Enugu, but much lower than the 56 cases per 10,000 reported in Switzerland [24] and other developed countries [2].

Although the actual incidence of intussusception in children is not known in our environment, most of the cases would normally present to the teaching hospitals where the specialists will be found to attend to the cases.

However a few of the cases of intussusceptions could have been mis-diagnosed in other levels of health care like primary health centres run by community health extension workers (CHEWs) and in some private hospitals and may not have been reported.

This study shows that the incidence of intussusception was increasing despite the non-use of the rotavirus vaccines in the cases reported. This could be as a result of increased knowledge and awareness of intussusception over time among health care providers. However, in countries where rotavirus vaccines have been introduced into the routine immunization schedules the incidence of intussusception has been shown to vary with some reporting no increase while others have reported a slight increase in the incidence of intussusception cases among vaccines [25].

The peak age incidence was in infants aged 6 months. This is similar to the findings in other studies [21] [26] [27]. However, a similar study among Taiwanese children reported peak age in children 1 to 3 years [28]. All these cases were in under-five children who are known to be the highest contributor to mortality in developing countries.

Males were predominantly affected compared to their female counterparts as previously reported by other workers [29].

Seasonal variations in the occurrence of intussusception remain controversial; while some workers have reported some variations [30] [31]. Others have noted no variation [28].

Findings from the current study show that majority of cases occurred between the months of December to April which corresponds to the rotavirus diarrhoeal season as previously reported in a Nigerian study [11].

Although our study did not screen for associated rotavirus infection among the cases of intussusception studied because of its retrospective nature several viral infections including rotaviruses, and adenoviruses [20] [32] have been reported to be associated with intussusception.

The average duration of symptoms prior to presentation was 4.1 days (range 10 hours to 8 days). Other studies in Enugu [22] and elsewhere in sub-Saharan Africa [33] [34] have reported similar findings. This late presentation will ultimately affect the clinical outcome either in terms of morbidity and/or mortality.

The common clinical presentations were vomiting, fever, passage of red currant stools, diarrhea, abnormal/ absent bowel sounds and abdominal distension. Similar findings have been reported by other researchers [35] [36]. It follows that due to ignorance some of the caregivers may not know when the red-line is crossed in terms of acute diarrhoea which they mostly attribute to "teething" especially in infants and acute intestinal obstruction like intussusception as most of them may first try self-medications including herbal concussions at home. This probably explains the observation of late presentation in majority of the cases studied with its attendant risks.

On presentation to the hospitals, even though more than one investigative tool was employed to make the final diagnosis of intussusception in many cases, abdominal ultrasonography stands out as the single most specific and predictive model of diagnosis. Other workers have equally reported similar experience [1] [37].

Majority of the cases in our series had laparotomy for their intussusception. This might be as a result of their late presentation resulting in complications with possibility of failure of other conservative methods of treatment like hydrostatic reduction. Higher rates of surgery lead to higher medical costs and longer median hospital stay [28] as seen in the current study.

Generally, the case fatality rate observed was 5.0\%. This was lower than $23 \%$ reported at Ile Ife, Nigeria [35].

Late presentations may arise mainly from ignorance, misconceptions, poverty and poor access to tertiary health care. This may lead to self-medication and patronage of patent medicine dealers making caregivers to present only when their expectations are not the obvious.

\section{Conclusions}

From the current study, intussusception is a common childhood surgical emergency. However, most cases present late with the result that majority of cases will be subjected to laparotomy. None of the cases of intussuscep- 
tion had confirmation of rotavirus vaccination.

Hence efforts should be made to expand intussusception studies across the country to establish a good baseline to be able to unravel any relationship between rotavirus infection, rotavirus vaccination and intussusception when rotavirus vaccine is introduced in the national immunization program. Also, post-licensure prospective surveillance studies should be continued after the introduction of the new rotavirus vaccines into the national routine vaccination schedule.

\section{Acknowledgements}

Mrs Ngozi Nwankwo, Mrs Amara Okonkwo.

\section{Limitation}

Inability to screen for rotavirus infection in the cases studied because of its retrospective nature.

\section{Funding}

WHO thorough the WHO Regional Office for Africa. The authors have no conflicts of interest to disclose.

\section{References}

[1] Wyliue, R. (2000) Intussusception. In: Behrman, R.E., Kliegman, R.M. and Jenson, H.B., Eds., Nelson Textbook of Paediatrics, 16th Edition, W.B. Saunders Company, Philadelphia, 1142-1143.

[2] Bines, J.E. and Ivanoff, B. (2002) Acute Intussusception in Infants and Children: A Global Perspective. Vaccines and Biologicals. WHO/V \& B/02.19, World Health Organization, Geneva.

[3] Swischuk, L.E., John, S.D. and Swischuk, P.N. (1994) Spontaneous Reduction of Intussusception Verification with Ultrasound. Radiology, 192, 269-271. http://dx.doi.org/10.1148/radiology.192.1.8208951

[4] Bines, J.E., Ivanoff, B., Justice, F. and Mulholland, K. (2004) Clinical Case Definition for the Diagnosis of Acute Intussusception. Journal of Pediatric Gastroenterology \& Nutrition, 39, 511-518. http://dx.doi.org/10.1097/00005176-200411000-00012

[5] Henrikson, S., Blane, C.E., Konjok, K., Strouse, P.J., Di Pietro, M.A. and Goodsitt, M.M. (2003) The Effect of Screening Sonography on the Positive Rate of Enemas for Intussusception. Pediatric Radiology, 33, 190-193. http://dx.doi.org/10.1007/s00247-002-0848-7

[6] Sondheimer, J.M. (2003) Intussusception. In: Hay, W.W., Levin, M., Sondheimer, J.M. and Deterding, R.R., Eds., Current Pediatric Diagnosis and Treatment, 16th Edition, McGraw-Hill Company, New York, 616-617.

[7] Konno, T., Suzuki, H., Hutsuzawa, T., Imai, A., Katsushima, N., Sakamoto, M., et al. (1978) Human Rotavirus Infection in Infants and Young Children with Intussusception. Journal of Medical Virology, 2, 265-269. http://dx.doi.org/10.1002/jmv.1890020310

[8] Widdowson, M.A., Bresee, J.S., Gentsch, J.R. and Glass, R.I. (2005) Rotavirus Disease and Its Prevention. Current Opinion in Gastroenterology, 21, 26-31.

[9] Murphy, T.V., Gargiullo, P.M., Massoudi, M.S., Nelson, D.B., Jumaan, A.O., Okoro, C.A., et al. (2001) Intussusception among INFANTS Given an Oral Rotavirus Vaccine. The New England Journal of Medicine, 344, 564-572. http://dx.doi.org/10.1056/NEJM200102223440804

[10] Vaccine and Biologicals. Acute Intussusception in Infants and Children: Incidence, Clinical Presentation and Management—A Global Perspective, WHO. http://whqlibdoc.who.int/hq/2002/WHO_V\&B_02.19.pdf

[11] Tagbo, B.N., Mwenda, J.M., Armaha, Obidike, E.O., Okafor, H.U., Oguonu, T., et al. (2014) Epidemiology of Rotavirus Diarrhoea among Children Younger than 5 Years in Enugu, South East Nigeria. Pediatric Infectious Disease Journal, 33, S19-S22. http://dx.doi.org/10.1097/INF.0000000000000047

[12] Tate, J.E., Burton, A.H., Boschi-Pinto, C., et al. (2012) WHO-Coordinated Global Rotavirus Surveillance Network. 2008 Estimate of Worldwide Rotavirus Associated Mortality in Children Younger than 5 Years before the Introduction of Universal Rotavirus Vaccination Programmes: A Systematic Review and Metaanalysis. The Lancet Infectious Diseases, 12, 136-141. http://dx.doi.org/10.1016/S1473-3099(11)70253-5

[13] Parasher, U.D., Hummelman, E.G., Bresse, J.S., et al. (2003) Global Illness and Deaths Caused by Rotavirus Disease in Children. Emerging Infectious Diseases, 9, 565-572. http://dx.doi.org/10.3201/eid0905.020562

[14] Glass, R.I., Bresee, J.S., Turcios, R., Fischer, T.K., Parashar, U.D. and Steele, A.D. (2005) Rotavirus Vaccine; Targeting the Developing World. Journal of Infectious Diseases, 92, S160-S166. http://dx.doi.org/10.1086/431504 
[15] Steele, A.D., Patel, M., Parashar, U.D., Victor, J.C., Aguado, T. and Neuzil, K.M. (2009) Rotavirus Vaccines for Infants in Developing Countries in Africa and Asia: Considerations from a World Health Organization-Sponsored Consultation. The Journal of Infectious Diseases, 200, S63-S69. http://dx.doi.org/10.1086/605042

[16] Vesiwkari, T., Matson, D.O., Dennehy, P., Van Damme, P., Santosham, M., Rodriguez, Z., et al. (2006) Safety and Efficacy of a Pentavalent Human-Bovine (WC3) Re-Assortment Rotavirus Vaccine. The New England Journal of Medicine, 354, 23-33. http://dx.doi.org/10.1056/NEJMoa052664

[17] Ruiz-Palacios, G.M., Pérez-Schael, I.P., Velázquez, F.R., Abate, H., Breuer, T., Clmens, C., et al. (2006) Safety and Efficacy of an Attenuated Vaccine against Severe Rotavirus Gastroenteritis. The New England Journal of Medicine, 354, 11-22. http://dx.doi.org/10.1056/NEJMoa052434

[18] Bine, J.E., Patel, M. and Parashar, U.D. (2009) Assessment of Postlicensure Safety of Rotavirus Vaccines with Emphasis on Intussusception. The Journal of Infectious Diseases, 200, S282-S290. http://dx.doi.org/10.1086/605051

[19] Bines, J.E., Bentsi-Enchill, A. and Steele, A.D. (2009) Post-Marketing Surveillance of Rotavirus Vaccine Safety. World Health Organization, Geneva.

[20] Velazquez, F.R., Colindres, R.E., Grajales, C., Hernández, M.T., Mercadillo, M.G., Torres, F.J., et al. (2012) Postmarketing Surveillance of Intussusception Following Mass Introduction of Attenuated Human Rotavirus Vaccine in Mexico. Pediatric Infectious Disease Journal, 31, 736-744. http://dx.doi.org/10.1097/INF.0b013e318253add3

[21] Parashar, U.D., Gentsch, J., Shiel, W.J., Zaki, S.R., Glass, R., Bahn, M.K., et al. (2009) Population-Based Incidence of Intussusceptions and a Case-Control Study to Examine the Association of Intussusception with Natural Rotavirus Infection among Indian Children. The Journal of Infectious Diseases, 200, S277-S281. http://dx.doi.org/10.1086/605045

[22] Bines, J.E., Kohl, K.S., Forster, J., Zanardi, L.R., Davis, R.L., Hansen, J., Murphy, T.M., Music, S., Niu, M., Varriccho, F., Vermeer, P. and Wong, E.J. (2004) Acute Intussusception in Infants and Children as an Adverse Events Following Immunization: Case Definition and Guidelines of Data Collection, Analysis, and Presentation. Vaccine, 22, 569-574. http://dx.doi.org/10.1016/j.vaccine.2003.09.016

[23] Ekenze, S.O., Mgbor, S.O. and Okwesili, O.R. (2010) Routine Surgical Intervention for Childhood Intussusception in a Developing Country. Annals of African Medicine, 9, 27-30. http://dx.doi.org/10.4103/1596-3519.62621

[24] Buettcher, M., Baer, G., Bonhoeffer, J., Schaad, U.B. and Heininger, U. (2007) Three-Year Surveillance of Intussusception in Children in Switzerland. Pediatrics, 120, 473-480. http://dx.doi.org/10.1542/peds.2007-0035

[25] (2014) Rotavirus Vaccines-Balancing Intussusception Risks and Health Benefits. http://www.rotacouncil.org/news/commentary/rotavirus-vaccines-balancing-intussusception

[26] Boundrille, I.C., Phuna, K.B., Quak, S.H., Lee, B.W., Han, H.H., Verstraeten, T., et al. (2006) The Epidemiology of Paediatric Intussusception in Singapore: 1997 to 2004. Annals of the Academy of Medicine, Singapore, 35, 674-679.

[27] Fischer, T.K., Bihrmann, K., Perch, M., Koch, A., Wohlfahrt, J., Kåre, M., et al. (2004) Intussusception in Early Childhood: A Cohort Study of 1.7 Million Children. Pediatrics, 114, 782-785. http://dx.doi.org/10.1542/peds.2004-0390

[28] HO, W.L., Yang, T.W., Chi, W.C., Chang, H.J., Huang, L.M. and Chang, M.H. (2005) Intussusception in Taiwanese Children: Analysis of Incidence, Length of Hospitalization and Hospital Costs in Different Age Groups. Journal of the Formosan Medical Association, 104, 398-401.

[29] Chouikha, A., Fodha, I., Maazoun, K., Brahim, M.B., Hidouri, S., Nouri, A., Trabelsi, A. and Steele, A.D. (2009) Rotavirus Infection and Intussusception in Tunisian Children: Implications for Use of Attenuated Rotavirus Vaccine. Journal of Pediatric Surgery, 44, 2133-2138.

[30] Chen, S.C., Wang, J.D., Hsu, H.Y., Leong, M.M., Tok, T.S. and Chin, Y.Y. (2010) Epidemiology of Childhood Intussusception and Determinants of Recurrence and Operation: Analysis of National Health Insurance Data between 1998 and 2007 in Taiwan. Pediatrics \& Neonatology, 51, 285-291. http://dx.doi.org/10.1016/S1875-9572(10)60055-1

[31] Nelson, E.A., Tam, J.S., Glass, R.I., Parashar, U.D. and Fok, T.F. (2002) Incidence of Rotavirus Diarrhoea and Intussusception in Hong Kong Using Standardized Hospital Discharge Data. Pediatric Infectious Disease Journal, 21, 701703. http://dx.doi.org/10.1097/00006454-200207000-00019

[32] O’ Ryan, M., Lacero, Y., Peña, A. and Valenzuela, M.T. (2003) Two Year Review of Intestinal Intussusception in Six Large Public Hospitals in Santiago, Chile. Pediatric Infectious Disease Journal, 22, 717-721. http://dx.doi.org/10.1097/01.inf.0000078374.82903.e8

[33] Ameh, E.A. (2002) The Morbidity and Mortality of Laparotomy for Uncomplicated Intussusception in Children. West African Journal of Medicine, 21, 115-116.

[34] Carneiro, P.M. and Kisusi, D.M. (2004) Intussusception in Children Seen at Muhimbili National Hospital, Dar es Salam. East African Medical Journal, 81, 439-442. http://dx.doi.org/10.4314/eamj.v81i9.9217

[35] Adejuigbe, O., Jeje, E.A. and Owa, J.A. (1991) Childhood Intussusception in Ile-Ife, Nigeria. Annals of Tropical Paediatrics International Child Health, 11, 123-127. 
[36] Archibong, A.E., Usoro, I.N., Ikpi, E. and Inyang, A. (2001) Paediatric Intussusceptions in Calabar, Nigeria. East African Medical Journal, 78, 19-21. http://dx.doi.org/10.4314/eamj.v78i1.9106

[37] Usang, E.U., Inah, G.B., Inyang, A.W. and Ekabua, A. (2013) Intussusception in Children: Comparison between Ultrasound Diagnosis and Operative Findings in a Tropical Developing Country. African Journal of Pediatric Surgery, 10, 87-90. http://dx.doi.org/10.4103/0189-6725.115029 